\title{
MR augmented cardiopulmonary exercise testing - a novel method of assessing cardiovascular function
}

\author{
Emmanuel O Ako ${ }^{1 *}$, Nathaniel Barber², Grzegorz T Kowalik², Jennifer Steeden², Vivek Muthurangu ${ }^{2}$ \\ From 18th Annual SCMR Scientific Sessions \\ Nice, France. 4-7 February 2015
}

\section{Background}

Reduced exercise capacity is a common feature of many cardiovascular diseases. Quantitative assessment of exercise capacity is usually achieved by measuring peak oxygen consumption $\left(\mathrm{VO}_{2}\right)$. However, measuring peak $\mathrm{VO}_{2}$ alone neglects the different components of reduced exercise capacity: namely reduced cardiac output (CO) and oxygen extraction $\left(\Delta \mathrm{cO}_{2}\right)$. A better approach would be to simultaneously measure $\mathrm{VO}_{2}$ and $\mathrm{CO}$ and then calculate $\Delta \mathrm{cO}_{2}$. This could be achieved using MR augmented cardio-pulmonary exercise testing (MR-CPET)

The aims of this study were to demonstrate: 1 ) MRCPET is feasible and well tolerated, 2) peak $\mathrm{VO}_{2}$ in the MR scanner correlates with conventional peak $\mathrm{VO}_{2}$, and 3) variation in peak $\mathrm{VO}_{2}$ is related to both peak $\mathrm{CO}$ and peak oxygen extraction $\left(\Delta \mathrm{CO}_{2}\right)$ as calculated by the Fick equation.

\section{Methods}

17 healthy volunteers (21-55 years) underwent MR-CPET. Exercise was performed on MR-compatible ergometer (Lode, Groningen, The Netherlands) and $\mathrm{VO}_{2}$ was assessed using a commercial respiratory gas analyzer (Ultima, MedGraphics, St. Paul, USA) with a modified sampling tube that was MR compatible. Aortic flow was continuously measured using a previously validated UNFOLD-SENSE spiral PCMR sequence. Images were reconstructed using a graphical processing units card and analyzed using an in-house plug-ins for OsiriX software. Conventional CPET was also performed within 2 weeks of MR-CPET.

\footnotetext{
${ }^{1}$ The Hatter Cardiovascular Institute, University College London, London, UK Full list of author information is available at the end of the article

For both test, participants were asked to rate i) concern ii) comfort and iii) perceived helplessness.

\section{Results}

15 out of 17 volunteers completed exercise; exclusions were due to claustrophobia $(\mathrm{n}=1)$ and inability to master exercise technique $(\mathrm{n}=1)$. Reported concern and discomfort was higher with MR-CPET, although still within acceptable limits.

Peak $\mathrm{VO}_{2}$, peak $\mathrm{VCO}_{2}$ and VE showed strong correlation between conventional CPET and MR-CPET: $\mathrm{VO}_{2}$ peak $(\mathrm{r}=0.94, \mathrm{p}<0.001) ; \mathrm{VCO}_{2}(\mathrm{r}=0.87, \mathrm{p}<0.001)$; $\mathrm{VE}$ $(\mathrm{r}=0.88, \mathrm{p}<0.001)$. Resting and peak values $\mathrm{VO}_{2}, \mathrm{CO}$, $\mathrm{HR}, \mathrm{SV}$ and $\Delta \mathrm{cO}_{2}$ are shown in table 1. Multiple linear regression analysis demonstrated that both peak $\mathrm{CO}$ and $\Delta \mathrm{cO}_{2}$ were independent predictors of peak $\mathrm{VO}_{2}$ measured during MR-CPET (beta $=0.73$ and 0.38 respectively, $\mathrm{p}<0.0001$ ) and conventional CPET (beta $=0.78$, 0.28 respectively, $\mathrm{p}<0.0001)$. Representative $\mathrm{VO}_{2}, \mathrm{CO}$ and $\Delta \mathrm{cO}_{2}$ are shown in figure 1 .

\section{Conclusions}

MR-CPET is feasible, well tolerated and demonstrates physiology not apparent with conventional CPET. In

Table 1 Resting and peak values during MR-CPET

\begin{tabular}{cccc}
\hline & Resting & Peak & \\
\hline Variable & Mean (SD) & Mean (SD) & $\mathrm{p}$ \\
\hline Heart Rate (bpm) & $73.70(27.18)$ & $132.08(15.40)$ & $<0.0001$ \\
\hline Stroke Volume (ml/beat) & $106.63(30.91)$ & $110.36(27.76)$ & 0.42 \\
\hline Cardiac Output (I/min) & $7.59(4.67)$ & $14.36(1.73)$ & $<0.0001$ \\
\hline VO2 (I/min) & $0.25(0.77)$ & $1.56(0.07)$ & $<0.0001$ \\
\hline$\Delta$ O2content & $0.03(0.02)$ & $0.11(0.01)$ & $<0.0001$ \\
\hline
\end{tabular}



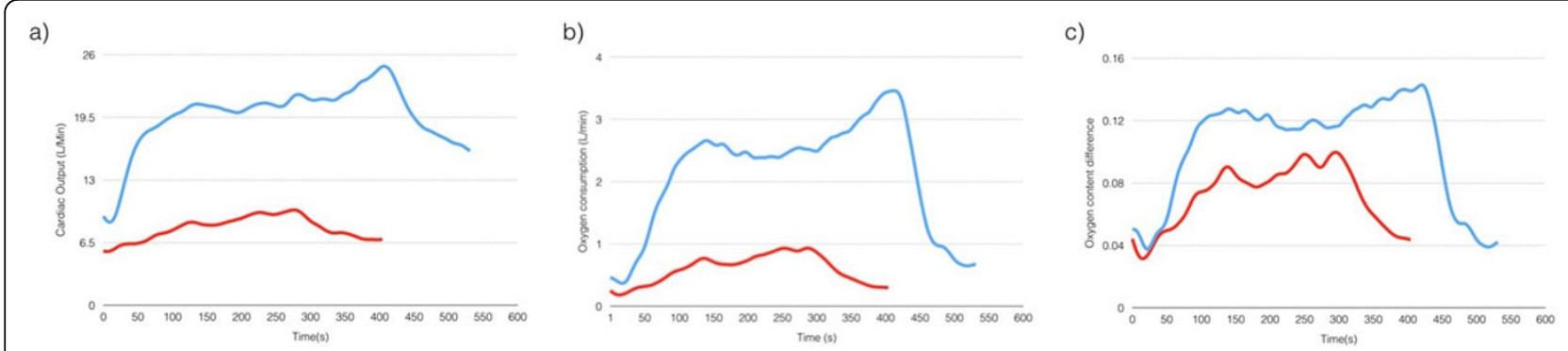

Figure 1

this study, we have shown that MR-CPET allows assessment of the differing contributions of $\mathrm{CO}$ and $\Delta \mathrm{cO}_{2}$ to variation in peak $\mathrm{VO}_{2}$. We believe that will be useful in understanding to origin of reduced exercise capacity in cardiac disease.

\section{Funding}

British Heart Foundation, Great Ormond Street Children's Charity.

\section{Authors' details}

${ }^{1}$ The Hatter Cardiovascular Institute, University College London, London, UK. ${ }^{2}$ UCL Institute of Cardiovascular Science \& Great Ormond Street Hospital for Children, London, UK.

Published: 3 February 2015

doi:10.1186/1532-429X-17-S1-Q2

Cite this article as: Ako et al:: MR augmented cardiopulmonary exercise testing - a novel method of assessing cardiovascular function. Journal of

Cardiovascular Magnetic Resonance 2015 17(Suppl 1):Q2.

Submit your next manuscript to BioMed Central and take full advantage of:

- Convenient online submission

- Thorough peer review

- No space constraints or color figure charges

- Immediate publication on acceptance

- Inclusion in PubMed, CAS, Scopus and Google Scholar

- Research which is freely available for redistribution

Submit your manuscript at www.biomedcentral.com/submit 